\title{
Navigating Family Involvement in Domestic Violence Fatality Review: Conceptualising Prospects for Systems and Relational Repair
}

\author{
James Rowlands ${ }^{1}$ (D) Elizabeth A. Cook $^{2}$ (i)
}

Accepted: 16 August 2021 / Published online: 28 August 2021

(c) The Author(s) 2021

\begin{abstract}
Purpose Family involvement is a key element of Domestic Homicide Review (DHR), the form of Domestic Violence Fatality Review (DVFR) found in England and Wales. Family involvement is framed as having dual purposes: first, as a benefit to DHRs, enabling a fuller picture of victims' experiences; second, as a benefit to families themselves, notably as a therapeutic or cathartic opportunity. However, these dual purposes have been little considered. This conceptual article responds to this absence by interrogating the purpose, process and outcomes of family involvement within DHRs.

Method To explicate purpose, process and outcomes, we synthesise policy, practice and the extant empirical and theoretical literature relating to family involvement in DHRs. We supplement this by engaging with a broader body of emerging research on family involvement in other review systems, analysing this through a lens of citizenship and participation.

Results Family involvement in DHRs is little explicated and there is a need to better engage with how family are involved in DHRs, as a way of increasing transparency for family rights. By way of response, a tentative conceptual framework is proposed which situates family involvement as demonstrative of systems- and relational-repair.

Conclusions The article concludes by arguing for greater attention to the Theory(s) of Change underpinning both the place of the family and their testimony, as well as the DHR system as a whole. Such clarity would benefit family, both as the subject of professional interactions but, critically, as agents in the DHR process in their own right.
\end{abstract}

Keywords Domestic homicide $\cdot$ Family $\cdot$ Repair $\cdot$ Fatality review $\cdot$ Theory of change $\cdot$ Participation

\section{Introduction}

Fatal domestic abuse ${ }^{1}$ is a significant issue in England and Wales. There were 357 domestic homicides ${ }^{2}$ recorded by police between April 2016 and March 2019 in England and Wales, and $77 \%$ (274) of these victims were women (Office for National Statistics, 2020). Patterns of coercive,

James Rowlands is a practising DHR Chair. In this capacity he has had professional contact (including collaboration) with AAFDA, the advocacy service described herein. He has also had contact with Victim Support's Homicide Service, to which reference is made in the article. With thanks to Frank Mullane, Sarah Dangar, and Philippa Tomczak for their comments on a previous draft of this article, and to the anonymous reviewers for their feedback. This work was supported by the Economic and Social Research Council (grant numbers: ES/P00072X/1 and ES/S011471/1).

James Rowlands

J.Rowlands@ sussex.ac.uk

1 Department of Sociology, School of Law, Politics and Sociology, University of Sussex, Freeman Building, BN1 9QE Brighton, England

2 Violence and Society Centre, City, University of London, EC1V 0HB London, England

\footnotetext{
${ }^{1}$ In this article, we use the term "domestic abuse" to capture a wide range of physical and non-physical harms which may precede death. This is particularly important for acknowledging deaths like domestic abuse-related suicides. However, in both practice and in the literature, it is commonplace to refer to "Domestic Violence Fatality Reviews". We use this term when referring to particular jurisdictions or the wider body of literature.

2 The Office for National Statistics (2020: p.22) defines a domestic homicide as "An offence of murder, manslaughter or infanticide where the relationship between a victim aged 16 years and over and the perpetrator falls into one of the following categories: spouse, common-law spouse, cohabiting partner, boyfriend or girlfriend, exspouse, ex-cohabiting partner or ex-boyfriend or girlfriend, adulterous relationship, son or daughter (including step and adopted relationships), parent (including step and adopted relationships), brother or sister, other relatives".
} 
controlling and intimidating behaviours commonly precede these fatalities. These patterns, some argue, indicate that domestic homicides are preventable if the circumstances leading up to the fatality are properly examined.

The introduction of Domestic Violence Fatality Review (DVFR) has been one response to these homicides and represents an intervention for increased visibility and insight into this pervasive, societal problem. Beginning in the United States, DVFR systems have since been established in a number of high-income countries including Australia, Canada, New Zealand, and Portugal, as well as England and Wales (where they are known as Domestic Homicide Reviews (DHRs) (Websdale, 2020). Comparisons of these different DVFR processes show differences reflecting the jurisdictional mandate for and manner of establishment and governance, the cases considered, operation, and reporting (Bugeja et. al., 2015). These differences have implications for how these different fatality reviews make sense of, and generate learning from, homicides (Rowlands, 2020a).

Although DVFR systems take different forms, they share a common approach. A multi-agency review team comes together to review domestic-abuse related deaths (most commonly, but not exclusively, intimate partner homicides) to understand the circumstances before a death and, based on any learning identified, making recommendations to improve responses to domestic abuse and prevent future homicides (Bugeja et al., 2015). Most review teams draw heavily on administrative (commonly court and police) data, which is then complemented by information from other agencies (Websdale et al., 2019). This data is largely from documented interactions between a victim and/or perpetrator and professionals.

Review teams may also draw on testimony from/of those who had a personal relationship with a victim, most prominently their family. ${ }^{3}$ The practice of involving families is increasingly recognised as a valuable, if challenging, part of DVFR, though there has been some hesitancy in doing so. This reflects practical concerns, including confidentiality, as well as the emotional burdens of contributing. These concerns centre around a family's experience of loss, their post homicide journey (including the potential for alienation during the criminal justice process, insensitive treatment and/or lack of information) (Armour, 2002), and the risk of further (or re) traumatisation by the review itself (Jaffe et al., 2013).

Although the prospect of secondary victimisation is an enduring concern, it has not stopped consideration of

\footnotetext{
3 The focus of this article is on the victim's family, for example, a parent, sibling or other relative. However, DVFRs may also engage with other testimonial networks, including a victim's friends, colleagues and/or community memberships, and sometimes the perpetrator and their family.
}

family involvement in DVFR altogether. In this context, family involvement in DVFR may also provide a chance for accountability and renewed public confidence in the State's ability to protect citizens. As Websdale (2012, p. 27) writes, DVFR can locate families in closer proximity with the State and community, to "embody a potentially subversive democratic ethic that prioritizes community safety and security". Most notably, in England and Wales, the involvement of family is a central requirement in the DHR process and reflects a "unique" model of advocacy (Mullane, 2017 , p.260), one that is yet to be developed to the same extent in other jurisdictions. Family involvement can thus have broader implications for citizenship, community, and repair. However, the lack of empirical and theoretical literature on family involvement prevents a clear articulation of their place in review processes and their interactions with other active parties.

The key question that this article seeks to respond to is therefore: how is family involvement currently conceptualised in DHR in England and Wales? The article approaches this question in four parts. First, we summarise our analytical approach, locating family involvement within a broader framework of citizenship and participation. Second, we address the DHR system in England and Wales, summarising its distinctive governance and structure. Third, we tease out the tensions that emerge in the practice of family involvement, considering purpose, process and potential outcomes. In particular, we trace family involvement over the course of a DHR, offering a detailed examination of this process with relevance to both those involved in DHRs but also international readers for whom this may inform the development of family involvement in other DVFR systems. We also examine the evidence relating to outcomes for family involvement in DHRs and, given this is limited, additionally draw on learning from other review systems in England and Wales.

Finally, we bring together these issues to call for greater attention to the Theory(s) of Change underpinning DHRs. We do not contend that there is no Theory of Change per se but that assumptions embedded within interventions, such as DHR, require interrogation so that how and why an intervention works can be clearly articulated. A Theory(s) of Change would also identify which actors are asked to participate, how and at which stage, and with what outcomes in mind. The process of forming a Theory of Change may not necessarily arrive through consensus but through "adjudication" (Stame, 2004, p. 62) between multiple stakeholders (who, as we shall discuss, may have different notions of purpose or outcomes) (Pawson \& Tilley, 1997). Central to this realist approach to Theory(s) of Change is not the question of 'does it work?' but instead 'what works, for whom, and in what circumstances?' (Pawson \& Tilley, 1997). Such 
attention is essential if the prospects of family involvement in DHRs for repair are to be fully realised. With this in mind, and to provide a basis for further conversations and research, we conclude by presenting a tentative conceptual framework.

\section{Analytical Approach}

This article focuses on the DHR system in England and Wales ${ }^{4}$ because family can and may be directly involved in this process. In contrast, in other jurisdictions, family commonly feed into but are not typically part of DVFR. Thus, although family may be approached (perhaps being interviewed or invited to speak to a review team), they are often unable to access the findings from the DVFR specifically relating to their loved one because any deliberations are confidential (for example: Florida Coalition Against Domestic Violence, 2017). In other cases, family input is indirect, via for example their involvement in the coronial process (for example: Office of the Chief Coroner Province of Ontario, 2019). As a result, the final product the family can access is likely the anonymised, aggregated report produced by that review team, which may include anonymised vignettes of the victim (for example: New South Wales Domestic Violence Death Review Team, 2020). The DHR process in England and Wales is therefore unique with regard to family involvement.

Despite the rapidly expanding body of research into DVFR, as well as DHRs specifically, the involvement of families in fatality reviews has been little investigated. As a result, our knowledge of how family perceive their involvement is largely limited to personal accounts (Websdale, 2010). Thus, for the most part, how family are or are not involved is little analysed (for two exceptions: Lewis, 2014; Mullane, 2017). The lack of critical engagement prevents us from conceptualising family involvement and the position of family within a broader system of change. Indeed, questions remain about the purpose, value and role of family involvement across different types of fatality review (McCarroll et al., 2020) and how families operate in relation to other parties.

Such questions are important because DHRs, like all forms of DVFR, routinely involves actors from crime and justice, health, non-governmental organisations (like domestic abuse support services), and social services. However, this is not a form of pure "dialogic democracy";

\footnotetext{
${ }^{4}$ We focus on England and Wales for the purpose of this paper as DHRs have only been undertaken in Northern Ireland since December 2020 (see https://www.nidirect.gov.uk/articles/domestic-homic ide-reviews-dhrs) while in Scotland "multi agency domestic homicide reviews" have been proposed but have not yet been introduced (see https://www.gov.scot/policies/violence-against-women-and-girls/ equally-safe-strategy/).
}

review teams must navigate interactions between actors who occupy uneven fields of power and exercise their participation in different ways (Websdale, 2012: p. 32). It is within this contested space that any family involvement must occur. Yet, as Arnstein (1969) argues, for authentic citizen participation to take place, a reallocation of power is required that speaks to different gradations of decisionmaking, ownership, and respect. This can be considered a benefit for both procedural aspects and outcomes of participation. Addressing family involvement matters both for bereaved families who are already forced to contend with extreme emotional upheaval, but also for realising the place of family as citizens in terms of both their relationship with the State (i.e. following a homicide) and systems-change (i.e. the prevention of future domestic abuse, including domestic homicide).

Locating DVFR in a lens of citizenship and participation provides a useful framework through which to view the purpose of family involvement. Indeed, the relationship of citizens and State is central to normative justifications of the State's authority to regulate (dis)order. These accounts, as Zedner (2020: n.p.) writes, are "premised upon a contractarian account of the state-citizen relation, according to which, in return for the promise of state protection and good order, citizens are obliged to obey the law". Interventions are required to restore the contract between State and citizen, one that has been broken by violations. For victims, these violations are fatal. For victims' families, these violations disrupt expectations about safety (a violation which action to hold the perpetrator to account via prosecution may not address).

A DVFR can signal an intention to learn lessons to protect publics and public order, as well as rebuilding the relationship between State and wronged citizens (or at least, their surviving family). In this respect, DVFR might be considered an attempt by the State at (re-) enacting its responsibilities to citizens to learn from failures and prevent them from happening again. However, the lack of empirical and theoretical literature on family involvement inhibits a clear articulation of the place of family and their interactions with other parties in DVFR. Critically, that includes how any involvement is undertaken, including whether the invitation - both in its offer and delivery - is limited, partial or a means to a genuine partnership (Arnstein, 1969).

This article responds to this omission by examining the practice of family involvement in DHRs. We review all publicly available policy documents, published by the Home Office (the government department responsible for, among other matters, crime and justice) as part of their DHR series, ${ }^{5}$

\footnotetext{
5 https://www.gov.uk/government/collections/domestic-homicidereview.
} 
Table 1 List of Relevant Policy Documents Relating to DHRs

Home Office (2011) Multi-Agency Statutory Guidance For The Conduct Of Domestic Homicide Reviews

Home Office (2013a) Criteria for considering domestic homicide review reports

Home Office (2013b) Multi-agency Statutory Guidance for the Conduct of Domestic Homicide Reviews

Home Office (2016a) Domestic Homicide Reviews: Key Findings From Analysis Of Domestic Homicide Reviews

Home Office (2016b) Multi-agency Statutory Guidance for the Conduct of Domestic Homicide Reviews

Home Office (2021) Guidance for Domestic Homicide Review chairs-Support for families

Table 2 List of Expectations Relating to Family Members

a) meet with family members and others at the earliest opportunity and offer signposting to specialist and expert advocacy support services...

b) communicate, where appropriate, directly or, if preferred by the family, through a designated advocate...

c) take into account their ethnic, cultural and linguistic needs

d) make a decision regarding the timing of contact with the family based on information from the advocate and taking account of other ongoing processes...

e) ensure initial contact is made in person (but make clear there are different ways in which friends, family members and others can contribute to the review...)

f) ensure regular engagement and updates on progress through the advocate...

g) explain clearly how the information disclosed will be used... [and if it] will be published...

h) explain how their information has assisted the review and how it may help other[s]...

i) ...ensure... adequate time is given to the family to consider and absorb the report, identify if any information has been incorrectly captured and record any areas of disagreement...

k) maintain reasonable contact with the family... even if they decline involvement

k) invite the family to help create the change after the review

Note. Adapted from Multi-agency Statutory Guidance for the Conduct of Domestic Homicide Reviews, by Home Office, 2016b, pp 18-19

that provide guidance on conducting and/or quality assessing this process in England and Wales (see Table 1) and/or make explicit reference to the role or purpose of families within the review process. This enables the identification of key components of, tensions with, and the lack of coherent conception about, family involvement in DHRs and therefore implications for DHR practice and policy.

This is supplemented with insights from a broader body of research on family participation in other reviews processes. Here, sources were selected for inclusion if they reported on qualitative research directly with bereaved family members who had been involved in a death investigation process in the United Kingdom (UK) or the Republic of Ireland (ROI) including fatal work incidents, suicides, state-related deaths, and case reviews (for example, Morris et al., 2015; Ngo et al., 2018; Shaw \& Coles, 2007; Snell \& Tombs, 2011; Spillane et al., 2019). Although these review processes have different foci and governance structures, this literature highlights challenges in relation to family involvement and provides context to the particularities of the DHR system in England and Wales, which we turn to next.

\section{Domestic Homicide Reviews (DHRs) in England and Wales}

In England and Wales, DHRs were introduced in the Domestic Violence, Crime and Victims Act 2004 but were not implemented as a requirement until 2011 (Payton et al., 2017). Where a domestic abuse-related death (either a homicide or a suicide) is deemed to have met the threshold, ${ }^{6}$ a DHR is commissioned by the local Community Safety Partnership ${ }^{7}$ where the victim was normally resident. The Community Safety Partnership appoints an independent chair (hereafter: the chair) to lead a review team (known as the "review panel") comprised of representatives from the police, adult and child social services, health, probation, non-governmental organisations (notably domestic abuse support services), and other agencies as required for the case

\footnotetext{
${ }^{6}$ DHRs can be commissioned where the death of someone, aged 16 or over, has, or appears to have, resulted from violence, abuse or neglect by a family member, a former or current intimate partner, or member of the same household.

7 Community Safety Partnerships - or "Crime and Disorder Reduction Partnerships" - bring together a range of local agencies and have a statutory responsibility for reducing crime and disorder, substance misuse and re-offending in a local area.
} 
(for an account of the DHR process, including a critique of its unity as a national system, see Rowlands (2020a)).

The DHR system has a distinctive model offering involvement by, and specialist and expert advocacy support services (hereafter: advocacy services) for, families who have been bereaved by domestic homicide. In DHRs, family involvement is (at least in principle) a central requirement. The statutory guidance that governs the conduct of DHRs directs that families should be "integral" to DHRs and be treated as a "key stakeholder" (Home Office, 2016b, p. 17). This is in contrast to a family's status in the criminal justice process which, as Mullane (2017) explains, can be alienating for a bereaved family.

The development of the DHR system has been analysed elsewhere, but in explaining the role of family, accounts acknowledge the formative impact of the Pemberton Review (see Payton et al., 2017). The Pemberton Review was completed following the murder of Julia and Will Pemberton in 2003 (Walker et al., 2008). Although DHRs were in statute, the relevant legislation had not been implemented and the bereaved family, led by Julia's brother Frank Mullane, campaigned successfully to have a DHR. Frank Mullane later founded the charity, Advocacy After Fatal Domestic Abuse $(\text { AAFDA })^{8}$ which has set a standard for advocacy services, emphasising the importance of specialism and expertise in this work, as well as the value of peer support.

At the start of a DHR, family should be approached and invited to be involved. The nominal status afforded to family is evident in the inclusion of several rights, from the beginning to the conclusion of a DHR, in the statutory guidance, with the latest iteration setting out expectations in this regard (Home Office, 2016b, pp. 18-19) (see Table 2).

Yet, these practices of family involvement have developed over time. In its earliest form, the statutory guidance was primarily concerned with how family should be included in DHRs (Home Office, 2011, pp. 15-16). However, there was not a requirement for families to be notified about the decision to commission a DHR (Mullane, 2017). Later iterations of the statutory guidance strengthened the rights of family, notably requiring that they be notified of the decision as to whether or not to undertake a DHR (Home Office, 2013b, p. 9). Over time, families also acquired a degree of agency, perhaps best illustrated regarding the scope of the DHR, as set out in case-specific Terms of Reference. Here, family involvement moved from being something "to consider" (Home Office, 2011, p. 12), to a requirement that family be informed (Home Office, 2013b, p. 13), before family finally acquired "the opportunity to influence the scope, content

\footnotetext{
${ }^{8}$ AAFDA provides specialist and expert advocacy and peer support to those left behind after domestic homicide. For more information, go to: https://aafda.org.uk.
}

and impact of the review" (Home Office, 2016b, p. 17). As agents in a DHR, the purpose of family involvement was articulated as "allowing the Review Panel to get a more complete view... in order to see the homicide through the eyes of the victim and/or perpetrator" (Home Office, 2013b, p. 16). It is of note that, preceding this description, the notion of family involvement informing a DHR is premised on it being "constructive", which carries an implicit question of what constructive involvement is and who makes this judgement. Having said that, family contributions were also recognised as being nuanced, with the current guidance noting that they may provide "factual information as well as testimony to the emotional effect of the homicide" (Home Office, 2016b, p. 17). As part of a quality assurance assessment process, chairs are required to evidence the nature of family involvement (or their attempts to involve families) (Home Office, 2013a). However, while policy has increasingly recognised the value of family involvement, practice is opaque regarding how family are involved and to whose benefit. In the following section, we present our analysis of relevant policy documents and existing literature.

\section{Tensions in Family Involvement: Purposes, Process and Outcomes}

\section{Locating Family Knowledge}

In England and Wales, when referring to the involvement in DHRs of those who had a personal relationship with a victim, in particular family, these types of relationships have been described as "informal networks" (Sharp-Jeffs \& Kelly, 2016, p.45). Looking beyond DHRs, this term developed to recognise and better account for the role of friends and family in outcomes for survivors (Gregory et al., 2017; Klein, 2012).

Describing testimony of this kind as being from an "informal network" is potentially problematic. First, testimony itself is not neutral, being subject to an assessment by a listener as to its trustworthiness. Testimonial "trustworthiness" can be reduced if the speaker is perceived to have a lesser authority to speak and/or if a listener's prejudice undermines the veracity of an account. Fricker has described this as an "epistemic injustice" (2007). In the context of a DVFR, where different sources of information are brought together, depending on how the role of family is understood and the value of their contribution is perceived, a review team may be more or less able to hear their testimony (Stauffer, 2015). Second, and reflecting an assessment of trustworthiness, the descriptor "informal network" juxtaposes this knowledge against the "formal" knowledge generated by practitioners, while also simultaneously implying it to be of lesser status or more unreliable (Monckton Smith et al., 2014). Yet, depending on how 
the purpose of the DHR is framed, and how the role of the State and citizen-family is understood, family knowledge may be of no lesser epistemic value than knowledge derived from the accounts of practitioners. Indeed, family and practitioner accounts are both derived from interactions with victims, perpetrators or children and can be described as ways of experiential knowing (Heron \& Reason, 1997), albeit mediated through different social relations and contexts. For this reason, we refer to "testimonial networks".

\section{Purpose of Family Involvement}

The rationale and purpose for family involvement are often framed through a dual-lens: the first speaks to a form of systems-repair that family testimonies might help enable and the second to the possibility of relational-repair for family through their participation in a DHR.

In terms of systems-repair, family can be conceptualised as contributing to the functioning of the DHR process, both in the diagnosis and identification of any system-failures before a death, as well as their involvement in generating potential solutions. This is, in part, a recognition that reliance on administrative data and practitioner accounts will only produce a partial picture, with family being a rich source of additional information (Sharp-Jeffs \& Kelly, 2016; Websdale, 2020). There is a body of evidence that demonstrates high rates of disclosure by victims to family and friends about the experience of intimate partner violence (Gregory et al., 2017; Klein, 2012). Family, therefore, offer potential insights unknown to administrative data. Through a feminist lens, Sheehan et al. (2015) conducted phenomenological interviews with family and close friends bereaved by intimate partner homicide which demonstrated the first-hand knowledge that these networks possessed regarding the barriers to accessing services and forms of controlling behaviour that their relative experienced, as well as indicators of risk and lethality. The input of families is therefore of benefit, principally because they may bring information (about a victim's experiences, contact with services, etc.) that would otherwise be unknown and/or unavailable to agencies. The breadth of understanding this allows is conceptualised as enabling a DHR to "see the homicide through the eyes of the victim and/or perpetrator", "help[ing] the panel understand the decisions and choices" they made by bringing, through family testimony, "different perspectives of the case" (Home Office, 2016b, p. 17). ${ }^{9}$

\footnotetext{
${ }^{9}$ A perpetrator, usually after the conclusion of the criminal trial, may also be invited to contribute to a DHR. Clearly, while there may be benefits to perpetrator involvement, including understanding their contact with services and/or identifying potential opportunities to intervene, there are also risks. Their involvement may offer a perpetrator a way to justify their behaviour, or even abuse after a death by way of any account offered. This practice, its extent, and if and how perpetrators contribute, is unknown and is beyond the scope of this article.
}

Meanwhile, relational-repair can be conceptualised as premised on the presumed therapeutic or cathartic value of family involvement in a DVFR process (Jaffe et al., 2013). The limited research in this area has signalled potential benefits to families such as opportunities to tell their story, make sense of what happened, and being able to contribute to a process that might prevent future homicide (Monckton Smith et al., 2014; Mullane, 2017). Websdale (2012) views DVFR through a lens of civic engagement and accountability, describing how family involvement can bring review teams into closer contact with communities and foster a sense of cohesion and ownership of problems between different agencies. For families, this perhaps offers an opportunity for repair, counter-balancing the sometimes clinical nature of providing testimony in courts or to the police, particularly due to the "forensic" narratives that centre the perpetrator (Monckton-Smith, 2012). This speaks to the possible relational-repair that these processes can offer: the potential to make sense out of a traumatic event (by, perhaps, an improved understanding of what happened before the death and/or having any questions answered, see Mullane, 2017) and, as a result of being part of systems-repair, be part of a dialogue that seeks to prevents these incidents from happening again, as well as the potential for repair to relations between citizen and State (Mullane \& Welch, 2013). This duality mirrors, for example, the experience of survivors of domestic abuse, for whom participating in research may be both difficult and simultaneously lead to gains, not least being heard and the opportunity to help others (Buchanan $\&$ Wendt, 2018).

Taken together, these conceptions of systems- and relational-repair illustrate the way that DHRs can be understood as a intervention to develop an alternative narrative of a homicide. Thus, there is a recognition that administrative data and practitioner accounts have limitations and that, within a DHR, families may be able to share different kinds of information, with this being of benefit to the findings of the DHR itself. These different concepts of purpose can materialise in different aspects of family involvement which shall be explored in the next section. Yet, despite the centrality of family involvement, how this is understood and its mechanisms, are largely unexplored. It is to these we now turn.

\section{Process of family involvement}

Although family involvement is held central to DHRs, its shape or form is unclear. The most recent guidance released around supporting families includes no substantive advice as to how to work with families, beyond re-stating the statutory guidance requirements and describing a referral pathway to advocacy services (Home Office, 2021). This dearth is reflected in the literature, with little published on how 
family engagement is undertaken and reported on in DHRs. Sharp-Jeffs and Kelly (2016) represent one exception: they identified that the level of family involvement varied considerably and that the methods used to engage families are not always clear. The actual practice of family engagement is therefore little documented.

The role of advocacy services in explicating exactly how DHRs can better involve families is influential. In this context, AAFDA have identified several key aspects, including raising the status of family, valuing their contribution, communication and regular updates, and delivery on commitments (see also Mullane, 2017). ${ }^{10}$ Here, family involvement is understood to have the potential to develop preventative responses. However, in practice, it is not clear how these aspects are understood by those involved in DHRs, including if they inform practice and enable family to be integral to the DHR process.

In approaching families, usually, the chair acts as the interlocutor, albeit often assisted by an advocacy service. Frequently, an initial approach is facilitated via a police Family Liaison Officer ${ }^{11}$ and should also have been preceded by contact by the Community Safety Partnership, explaining the decision to conduct the DHR. However, there can be delays in making contact commonly because, in contrast to DVFR processes internationally, DHRs commence at the point of the homicide. Thus, the criminal proceedings may initially limit family involvement (Benbow et al., 2019; Sharp-Jeffs \& Kelly, 2016).

There is evidence that indicates family do want the option to participate in learning exercises after domestic homicide, including DHRs. In one recent study, in nearly half (45\%) of the DHRs sampled, there was information indicating that the family (or friends) were aware of domestic abuse within the relationship, suggesting they contributed (Chantler et al., 2020. This finding was replicated in a report into DHRs in London, which reported over half (56\%) of the sample had family involvement (Montique, 2019).

However, these indicative results suggest that in around half of DHRs, family do not participate. Whether this is by choice or because of issues with how they were approached is unclear. For example, although it has been recommended that repeated approaches should be made (Montique, 2019), the practices adopted by different chairs have not been

\footnotetext{
$\overline{10}$ AAFDA have developed a 7-step model to underpin the role of family in DHRs. For more information: https://aafda.org.uk/resou rces/AAFDA's\%207\%20step\%20model\%20for\%20working\%20with\% 20families\%20in\%20DHRs.

11 There is also little empirical research into the role of the Family Liaison Officer, who may have already provided basic details and rationale for the DHR before a family is introduced to the chair. Thus, a Family Liaison Officer could influence how a family first understand and then go onto engage with the DHR process.
}

investigated. As a result, an unknown number of families, in line with the statutory guidance, may be approached soon after a homicide (when they may be least likely to engage), with a non-response being taken as an informed decision not to be involved.

A further complication is the absence of an agreed definition of family. This means 'family' is not always interpreted consistently (including how widely this is interpreted and thus who is included and excluded, including at the point of the first approach) and/or may be viewed as a homogenous unit. In some circumstances, relatives may act as gatekeepers and may refuse access to other family members (even if others wish to participate). There may also be fractured relationships, particularly given that a homicide is a traumatic life event. There may also be disagreements about participation or contradictory accounts of the victim and/ or perpetrator, while in the course of their involvement, one family member may reveal information about other family members without their consent. As a result, in practice, family dynamics and relationships are much more complex than identifying a single point of contact.

Family can include both relatives of victims and perpetrators, particularly in cases of adult family homicide (Home Office, 2016a). In their study of 32 DHRs, Sharp-Jeffs and Kelly (2016) speculated that a kinship relationship makes participation more difficult as the family is frequently related to the victim and perpetrator. They noted that only a quarter of adult family DHRs had family involvement (25\%), which was less than half of the rate in intimate partner homicide DHRs (58\%). While studies to date have taken steps to explicate what this may mean conceptually in terms of the differences between intimate partner and adult family homicide (Benbow et al., 2019; Sharp-Jeffs \& Kelly, 2016), by and large, they have not addressed implications for the DHR process itself. The extent to which DHRs engage with the families of perpetrators in intimate partners homicides is also unknown.

References to family may also obscure the involvement of children bereaved by domestic homicide, as these tend to refer to an adult family member(s). There has been a developing understanding of the impact of domestic homicide on children, which has been described as a "unique combination of trauma, loss and hardship" (Alisic et al., 2017, p. 2). In this context, DHRs may be a potentially important tool to attend to the experience of children after domestic homicide, considering both their support but also their involvement. Yet, although the statutory guidance recommends that children should have specialist support (Home Office, 2016b, p. 17), practice here is fraught with complexities and little understood.

There is also an unacknowledged question as to whether family can indeed give voice to homicide victims by way of their testimony. Previous research speaks to the capacity 
of families to "speak for and about the living and the dead" as both personal and political activist responses to violent bereavement (Cook, 2021; Rock, 1998, p. 128). This thinking may also be extended to DHRs, with relatives acting as proxy voices for the deceased, so reasserting the centrality of the victim. However, there is little known about what this means in practice.

That advocacy services are presumed to have a central role in this context speaks more broadly to an active voluntary sector that supports victims of serious violence (Rock, 2000). Yet, one recent study concluded that the involvement of these services was relatively low, with just under a fifth (19\%) of families known to have had such support (Montique, 2019). While this figure should perhaps be treated with caution - as the data was drawn from 84 DHRs conducted between 2011 and 2018 in only one region, and as reported may include double counting - it does raise questions about the robustness of the pathway to, or perhaps the efficacy of, the advocacy service model. Understanding what constitutes best practice in terms of specialist and expert advocacy is critical, particularly given recent changes to their commissioning (a sub-contracting arrangement between AAFDA and the provider for the UK Government's Homicide Service (Victim Support) ended in March 2020, and the latest guidance (Home Office, 2021) does little to clarify working practices between the services).

If families do engage, they have several opportunities to influence the DHR. This includes, if they are involved from the start, influencing the Terms of Reference, perhaps by identifying any questions they want asked or concerns they want explored. Family may then go onto contribute directly. Most commonly, this is by way of an interview with the chair, although family may also meet the review panel. However, there is no published research documenting how these encounters are conducted or how the information gathered is then used to inform review panel discussions or textually within the published DHR, although others report that family voice can be given less weight (Robinson et al., 2019). Critically, it is unclear if, why and how family testimony is left unused by DHRs.

Family should also have the opportunity to see and comment on the draft report of the DHR, including the option to "record any areas of disagreement" (Home Office, 2016a, p. 19). It is also important to note that family involvement should not be presumed to conclude prematurely, for example at the point the DHR report is published. In addition to being consulted around publication, family may also wish to be part of the process of monitoring the implementation of recommendations (again, if and how this happens is unclear).

Collectively, as with many other aspects of the DHR system, it is uncertain to what extent and by what manner these different opportunities for involvement are offered, as well as how this may vary by area. Such variance might reflect practices of an individual chair or the responsible Community Safety Partnership, but also perhaps the processes of negotiation between various stakeholders that might create a hierarchy of testimony. Families lack automatic status in DHR and, therefore, their testimony must be self-advocated or advocated by others. Collectively, this highlights the interdependencies between system- and relational repair: DHRs may counter-balance the aforementioned forensic narrative and contribute to systems-repair (particularly if the lessons produced are primarily consumed by systems), while simultaneously relational-repair is impeded as a consequence of epistemic injustice.

\section{Outcomes of family involvement}

Considering research to date, we know very little about family (and others) experience of DHRs, beyond a small number of previously mentioned family accounts, including feelings about, and satisfaction with, their involvement and the outcomes achieved (Rowlands, 2020a). However, there are two notable exceptions.

The first is based on an account of working directly within an advocacy service for families involved in DHRs and, as proposed, could be understood as an example of authentic citizen participation (Arnstein, 1969). Here, Mullane (2017) identified five outcomes of family involvement. First, families can corroborate and correct the victim and perpetrator histories presented by agencies, enabling a more accurate account. Second, families can provide insight into what services looked like to victims, how they perceived barriers to access, and possible improvements. Third, families can offer knowledge of service experiences that agency representatives do not hold. Fourth, the process "may provide comfort for families when they feel it has provided answers to their questions and attempted to address future safety issues" (Mullane, 2017, p. 270). Finally, this model can position families as drivers of change where they perceive it is needed most.

The second is based upon a study of family engagement with DVFR in the United States (Lewis, 2014). This study identified some important findings, not least that while participation could be challenging, it was also often positive (in both instances, for the reasons stated above). Yet, there were issues here too: for example, a lack of follow-up with, and feedback to, family was also reported. This study is itself illustrative of the challenge of family involvement: family members were not themselves participants, instead, data were drawn from interviews with review team members about their perspectives on this issue.

The evidence regarding outcomes of family involvement is therefore limited. However, there is emerging research that discusses family involvement in other review processes 
in England and Wales from which some comparable observations might be drawn. This body of work examines families' experiences of case reviews (Morris et al., 2015), state-related deaths (Shaw \& Coles, 2007), coronial inquests into fatal work incidents (Ngo et al., 2018; Snell \& Tombs, 2011), and suicides (Spillane et al., 2019), and reports a mixed experience for families. These different review processes do not work in the same manner as DHRs (including how they involve family) and such differences are beyond the scope of this article to describe. However, they are all examples of how statutory inquiry encounters family and thus illuminate the potential benefits and costs of family involvement.

In the context of case reviews where a child has died or been severely injured as a result of abuse or neglect, Morris et al. (2015) investigated rationales for family participation. Based on interviews with professionals, advocates, and families, they suggested four broad drivers for family involvement: family involvement as a fundamental right; keeping the child central through the family accounts of their life; family testimony as a source of knowledge; and in recognition of altruistic and cathartic motives (Morris et al., 2015, p. 202). The practitioner approach to family participation is important here as it speaks to the perceived purpose of family involvement and how their testimony is utilised.

In the context of state-related deaths, such as deaths in custody, the inquest process reflects a similar dynamic of active inter-agency working and a lack of provision for the support of families through the system. A report, published by INQUEST, ${ }^{12}$ speaks to this, presenting findings from questionnaires, interviews and casework studies with bereaved families (Shaw \& Coles, 2007). Among the challenges that families faced during the process were issues such: as access to legal representation; lack of timely and sensitive information regarding how the death would be investigated and how family could participate; feelings that families were being investigated rather than the circumstances leading up to the death; and the variable disclosure of investigative reports. Indeed, Shaw and Coles reported that over two-thirds of families were dissatisfied with the inquest, in both process (how they were treated) and impact (what the outcome was) (2007).

The involvement of advocacy support, such as that provided by INQUEST and AAFDA, can be an important factor in supporting families through the process. Yet not all bereaved families have access to support. Snell and Tombs (2011) investigated fatal work incidents in the coronial

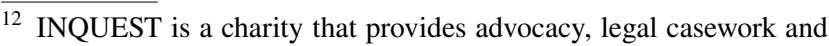
expertise on state-related deaths such as those that occur in immigration detention, prison, police custody, care and mental health settings. For more information, go to: https://www.inquest.org.uk/.
}

process, commenting on some families' sense of loss of control. The authors concluded that: "The majority of the families found no solace in the official conclusion, and many were left to blame themselves for lacking the knowledge and finances to continue the fight" (Snell \& Tombs, 2011, p. 216). This may have the adverse effect of amplifying and exacerbating the grief of bereaved families, rather than relieving it.

The available research on suicide-bereaved family experiences of inquests is comparable. Although some families report positive outcomes, inquests can also compound grief. Spillane et al. (2019) reported on qualitative interviews with 18 suicide-bereaved family members in Cork, Ireland. They demonstrated that a lack of information and clarity in the process and the rigid structure imposed by the inquest system (in particular, as these are public in Ireland) led to heightened emotional distress.

Within the context of prison suicide, families can find inquests intimidating, which risks re-traumatising those who are already dealing with complex grief without any publicly funded specialist support. Tomczak (2018) notes the complicated experience of families in prison-suicide inquest processes in England and Wales because of the multiple agencies involved in death investigations. The lack of legal representation and reliable access to decisions, information and verdicts can create substantial burdens upon families. Thus, while inquests may potentially provide "closure" and the alleviation of blame and guilt (Spillane et al., 2019, p. 7 ), it is uncertain if this is always achieved.

While these review processes are very different to DHRs, the evidence from these other systems highlight the key sites of tension in the (perceived) outcomes of family involvement. These tensions are illustrative of a lack of clear Theory(s) of Change and the place of families within DHRs. The following section considers the implications of these tensions and highlights the need to articulate a Theory of Change, not only for respecting the emotional burdens of the process but situating families as actors in achieving change.

\section{Tensions as illustrative of the absence of a clear Theory(s) of Change}

In explicating the purpose(s), process(es), and outcome(s) of family involvement, we have identified some of the tensions that may arise. Moreover, the failure to articulate this within the DHR system may lead to unevenly applied practices, miscommunications over purpose, and a lack of transparency about what is expected of both families and practitioners. These raise several questions and point to sometimes contradictory practices. If family testimony is so critical to a DHR (and also contributes to relational-repair for families), why is information not 


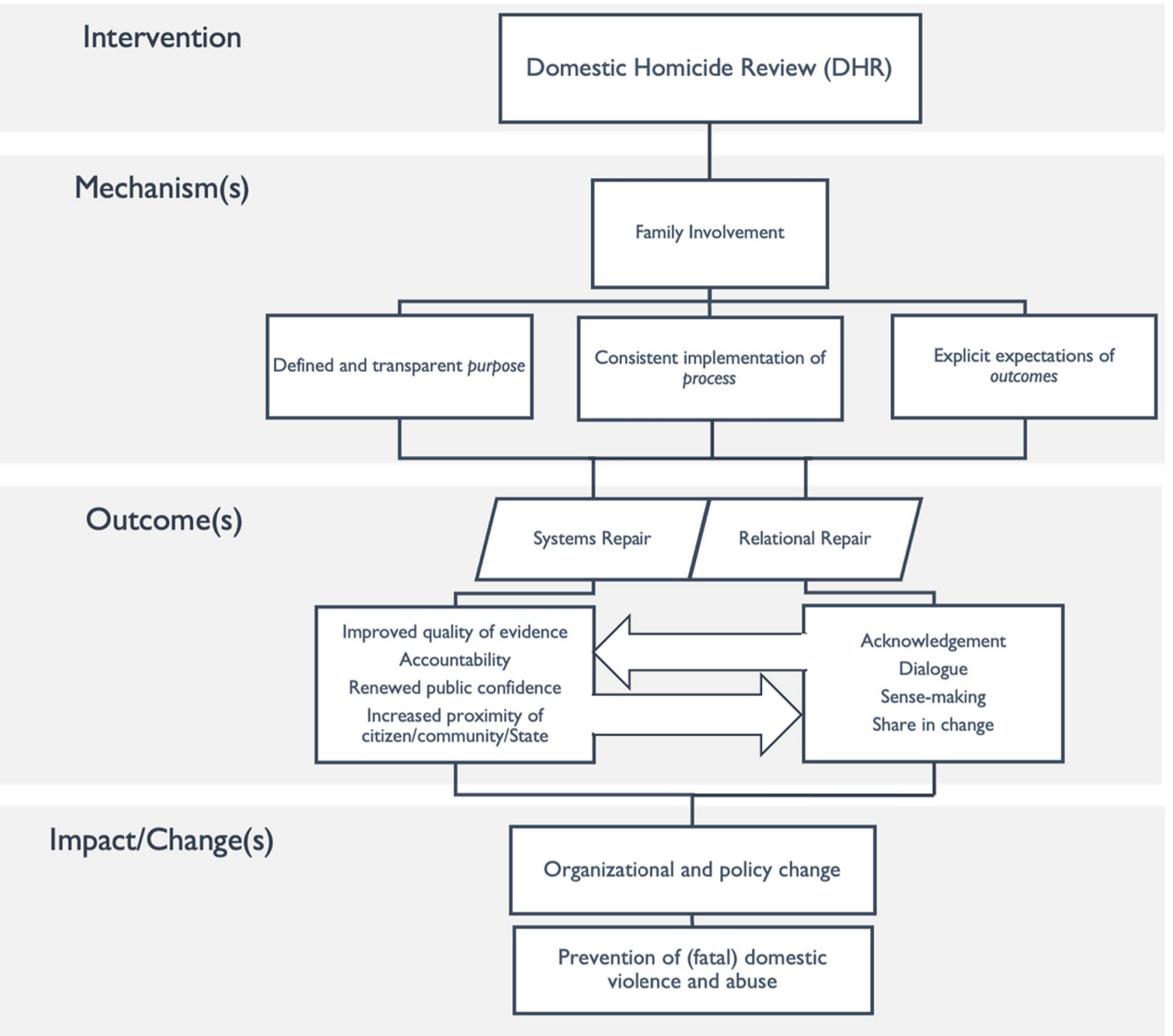

Fig. 1 A Tentative Conceptual Framework of Family Involvement in DHR

more consistently communicated to families and practice inconsistent? If the aim of DHR is system-repair (including structural reform), does family testimony fall to the periphery? If relational-repair is in part dependent on the achievement of system-repair, how can families hold agencies to account for implementing change (and critically, how can agencies re-allocate power to ensure this happens)? Without articulating Theory(s) of Change which captures different perceptions of purpose, process and outcome, we cannot recognise conflict nor the potential for alignment. Moreover, without an articulation of the place of family in such a theory, we lack knowledge about which forms of testimony are considered of epistemic value. Approached through a lens of citizenship and participation, and by way of response, a conceptual framework is presented below which situates family involvement as demonstrative of systems- and relational-repair and connects it to the prospect of prevention (Fig. 1).

The scarcity of empirical research on family needs and their experiences of DHRs (and other review processes) is a point that we have returned to frequently in this discussion. As such, we offer this as a framework tentatively as a way to begin to imagine the key components of family involvement, as identified in this paper, and how they might interact with one another.

In our framework, we identify the DHR as the key intervention and family involvement as one (of many) mechanism(s) within DHR which provide opportunities for two symbiotic outcomes: systems- and relational-repair. These forms of repair are dynamic in their effect. For 
example, providing families with a stake in change might increase public confidence and accountability for policymaking on domestic abuse (Websdale, 2012). Similarly, if a DHR can show a demonstrable change through, for example, reforming organizational practices, and this can be communicated to families, those involved in DHR can better recognise the emotional burdens of family involvement.

The process of identifying the Theory(s) of Change standardises the what and how of achieving change but also makes explicit who (i.e. families) should be involved and at which stage (Stame, 2004; Pawson \& Tilley, 1997). This is particularly important when, as part of the DHR, a review panel considers material and testimonies from such a range of sources (including administrative data, as well as accounts from testimonial networks). The offer of a platform to participate, as Websdale (2012) notes, is one mechanism by which different forms of knowledge, albeit from different speakers with different status, come into dialogue.

In other words, a DVFR (including a DHR) is an opportunity for tabling different forms of knowledge. However, as Websdale (2012) recognises, there can be power imbalances in these exchanges. Perceived as a source of information, families may be situated as mere providers of information rather than having a stake in shaping findings, or as units who should have had increased awareness of abuse. This potentially overshadows other possible "benefits" of involvement. Returning to Arnstein (1969), this means any invitation to involvement may in reality not be participation at all, or at best tokenistic. Indeed, some argue that this risks family involvement being reduced to being merely "punctual": as Neuilly (2013, p. 343) writes in the context of the US, "in public health the public is considered as subject, the population on which prevention strategies are to be acted". Even in England and Wales, as noted previously, where family involvement is located within an advocacy model, there are reports that family voice can have lesser status (Robinson et al., 2019).

This speaks to the possibility of instrumentalization of family testimony. What is considered as expertise, or to be of epistemic value, is judged according to the perceived purpose: what knowledge is required to answer the question(s) posed by a DHR? The statutory guidance recognises this by pointing to the "risk of ascribing a "hierarchy of testimony" where some expertise or knowledge is prioritised over others (Home Office, 2016b, p. 17). This potentially overshadows other possible benefits of involvement, including relationalrepair between the State and citizens and risks instrumentalization of family testimony.

Without a clear articulation of purpose, the utilisation of family testimony is likely to be variable both by place and by person. Assumptions may be made about the capacity and resilience of families to manage their involvement in DHRs. While these assumptions may deprive some families of the support they need to participate, they also deprive others of the opportunity to contribute because of a perceived fear they are too vulnerable.

The lack of a clear Theory(s) of Change also presents problems for the intended and actual outcomes of involvement for families. For DHRs (and other review processes), there is a mixed picture of family involvement. It is unclear whether recommendations are fully implemented by agencies and, even more, whether these changes are communicated to families. This raises the question as to whether families would still be willing to contribute to the process without the promise of change (i.e. systems-repair). As such, DHRs may well be reparative for families, but there is a question of whether this in part depends upon achieving reform and accountability. Recognising this distinction, in the context of NHS inquiries, Ryan (2019, p. 227) argues for the term "leading to demonstrable change" rather than "lessons learned" to recognise the emotional investment families have in change and seeing it delivered. Articulating a clear Theory(s) of Change for DHRs would afford transparency in the seeking and use of testimony, but also be of benefit to family by clarifying their place as agents in the DHR process in their own right (including respecting the emotional work involved, the limits of participation, and prospects for change).

\section{Strengths and Limitations}

Although this article's examination of policy and practice, and its proposed tentative conceptual model, is a basis for further conversations and research, there are a number of limitations to the approach and material utilised. Firstly, the model of advocacy in England and Wales is, as mentioned above, unique and it is therefore both challenging to make comparisons with other jurisdictions and also to draw out the influence that advocacy, in comparison to the DHR system itself, has on family participation. Secondly, the lack of qualitative research with bereaved families regarding their experiences of DHR, among other reviews processes, prevents a more systematic account of families' experiences (particularly across the various, intersecting death investigation systems). To develop this further, there is an urgent need for empirical work to explore the role of, and outcomes for, family in DHRs.

\section{Conclusion}

A DHR comes about because, in part, there has been a fatal systems-failure to protect a victim of domestic abuse. The potential for these failings to be repeated within a 
DHR must be avoided. This is of conceptual and practical value but also an ethical imperative: what constitutes ethical conduct when involving family? There has been relatively little research into ethics in DVFR (Dale et al., 2017), although Albright et al. (2013) have emphasised the ethical implications of involving family, Bent-Goodley (2013) has pointed to the need for cultural competence, and Rowlands (2020b) has explored the ethics of victim voice. Yet, by any reckoning, engaging with bereaved families is a sensitive research topic. In this context, a feminist informed research ethics would question how participation is understood, with a particular focus on power (Ackerly \& True, 2020). We might ask: How should issues like informed consent, the rights of an interviewee, or aftercare be approached? How should testimonial network interviews be structured? And to what extent should testimonial networks be understood as co-constructing the knowledge produced by DHRs, with implications for how equal status is enacted? These questions also raise issues for the professionals in DHRs. One might ask about the skills of the chair as an interviewer, as well as their reflexivity, in particular regarding power imbalances, but also as an arbiter (with the review panel) of the representation of someone's loved one. Whether there is harm and/or benefit, there is emotional work in any involvement that should be recognised if we are to value the integrity of family testimony, not just as data, but as a memory of the deceased.

Open Access This article is licensed under a Creative Commons Attribution 4.0 International License, which permits use, sharing, adaptation, distribution and reproduction in any medium or format, as long as you give appropriate credit to the original author(s) and the source, provide a link to the Creative Commons licence, and indicate if changes were made. The images or other third party material in this article are included in the article's Creative Commons licence, unless indicated otherwise in a credit line to the material. If material is not included in the article's Creative Commons licence and your intended use is not permitted by statutory regulation or exceeds the permitted use, you will need to obtain permission directly from the copyright holder. To view a copy of this licence, visit http://creativecommons.org/licenses/by/4.0/.

\section{References}

Ackerly, B. A., \& True, J. (2020). Doing Feminist Research in Political and Social Science (2nd edition). Macmillan Education.

Albright, D., Banks, L., Broidy, L., Crandall, C., \& Campos, G. (2013). Ethical Conundrums in Fatality Review Planning, Data Collection, and Reporting: Viewing the Work of Review Teams Through the Lens of Evaluation. Homicide Studies, 17(4), 436456. https://doi.org/10.1177/1088767913498877

Alisic, E., Groot, A., Snetselaar, H., Stroeken, T., Hehenkamp, L., $\&$ van de Putte, E. (2017). Children's perspectives on life and well-being after parental intimate partner homicide. European
Journal of Psychotraumatology, 8(sup6), 1463796. https://doi. org/10.1080/20008198.2018.1463796

Armour, M. P. (2002). Experiences of Covictims of Homicide: Implications for Research and Practice. Trauma, Violence, \& Abuse, 3(2), 109-124. https://doi.org/10.1177/15248380020032002

Arnstein, S. R. (1969). A Ladder Of Citizen Participation. Journal of the American Institute of Planners, 35(4), 216-224. https:// doi.org/10.1080/01944366908977225

Benbow, S. M., Bhattacharyya, S., \& Kingston, P. (2019). Older adults and violence: An analysis of Domestic Homicide Reviews in England involving adults over 60 years of age. Ageing and Society, 39(6), 1097-1121. https://doi.org/10.1017/S0144686X1 7001386

Bent-Goodley, T. B. (2013). Domestic Violence Fatality Reviews and the African American Community. Homicide Studies, 17(4), 375-390. https://doi.org/10.1177/1088767913497949

Buchanan, F., \& Wendt, S. (2018). Opening doors: Women's participation in feminist studies about domestic violence. Qualitative Social Work, 17(6), 762-777. https://doi.org/10.1177/1473325017 694081

Bugeja, L., Dawson, M., McIntyre, S.-J., \& Walsh, C. (2015). Domestic/Family Violence Death Reviews: An International Comparison. Trauma, Violence, and Abuse, 16(2), 179-187. https://doi. org/10.1177/1524838013517561

Chantler, K., Robbins, R., Baker, V., \& Stanley, N. (2020). Learning from domestic homicide reviews in England and Wales. Health \& Social Care in the Community, 28(2), 485-493. https://doi.org/ $10.1111 / \mathrm{hsc} .12881$

Cook, E. (2021). Family Activism in the Aftermath of Fatal Violence. Routledge.

Dale, M., Celaya, A., \& Mayer, S. J. (2017). Ethical Conundrums in the Establishment and Operation of Domestic/Family Violence Fatality Reviews. In M. Dawson (Ed.), Domestic Homicides and Death Reviews: An International Perspective (pp. 229-256). Palgrave Macmillan.

Florida Coalition Against Domestic Violence. (2017). Domestic Violence Fatality Review: A Guide for Florida's Domestic Violence Fatality Review Teams. Author. https://www.fcadv.org/projectsprograms/attorney-general's-statewide-domestic-violence-fatal ity-review-team. Accessed 09 Apr 2020

Fricker, M. (2007). Epistemic Injustice. Oxford University Press.

Gregory, A. C., Williamson, E., \& Feder, G. (2017). The Impact on Informal Supporters of Domestic Violence Survivors: A Systematic Literature Review. Trauma, Violence, and Abuse, 18(5), 562-580. https://doi.org/10.1177/1524838016641919

Heron, J., \& Reason, P. (1997). A Participatory Inquiry Paradigm. Qualitative Inquiry, 3(3), 274-294. https://doi.org/10.1177/10778 0049700300302

Home Office. (2011). Multi-Agency Statutory Guidance For The Conduct Of Domestic Homicide Reviews. https://webarchive.natio nalarchives.gov.uk/20110922143440/http://www.homeoffice. gov.uk/publications/crime/DHR-guidance. Accessed 28 Nov 2018

Home Office. (2013a). Criteria for considering domestic homicide review reports. https://assets.publishing.service.gov.uk/gover nment/uploads/system/uploads/attachment_data/file/207602/crite ria-DHR-web-v2.pdf. Accessed 10 Apr 2020

Home Office. (2013b). Multi-agency Statutory Guidance for the Conduct of Domestic Homicide Reviews. https://webarchive.nationalar chives.gov.uk/20150402141623/https://www.gov.uk/government/ publications/revised-statutory-guidance-for-the-conduct-of-domes tic-homicide-reviews. Accessed 07 July 2020

Home Office. (2016a). Domestic Homicide Reviews: Key Findings From Analysis Of Domestic Homicide Reviews. https://assets. publishing.service.gov.uk/government/uploads/system/uploads/ attachment_data/file/575232/HO-Domestic-Homicide-ReviewAnalysis-161206.pdf. Accessed 07 July 2020 
Home Office. (2016b). Multi-agency Statutory Guidance for the Conduct of Domestic Homicide Reviews. https://assets.publishing. service.gov.uk/government/uploads/system/uploads/attachment data/file/575273/DHR-Statutory-Guidance-161206.pdf. Accessed 07 July 2020

Home Office. (2021). Guidance for Domestic Homicide Review chairs-Support for families. https://www.gov.uk/government/ publications/guidance-for-domestic-homicide-review-chairs-onsupport-for-families. Accessed 06 July 2021

Jaffe, P. G., Dawson, M., \& Campbell, M. (2013). Developing a national collaborative approach to prevent domestic homicides: Domestic homicide review committees. Canadian Journal of Criminology and Criminal Justice, 55(1), 137-155. https://doi. org/10.3138/cjecj.2011.E.53

Klein, R. (2012). Responding to intimate violence against women: The role of informal networks. Cambridge University Press.

Lewis, L. L. (2014). Examining family member involvement during the domestic violence fatality review process. [Doctoral dissertation, Capella University].

McCarroll, J. E., Fisher, J. E., Cozza, S. J., \& Whalen, R. J. (2020). Child Maltreatment Fatality Review: Purposes, Processes, Outcomes, and Challenges. Trauma, Violence, \& Abuse, 152483801990055. https://doi.org/10.1177/1524838019900559

Monckton Smith, J., Williams, A., \& Mullane, F. (2014). Domestic abuse, homicide and gender: Strategies for policy and practice. Palgrave Macmillan.

Monckton-Smith, J. (2012). Murder, gender and the media: Narratives of dangerous love. Palgrave Macmillan.

Montique, B. (2019). London Domestic Homicide Review (DHR) Case Analysis and Review of Local Authorities DHR Process. Standing Together Against Domestic Violence. https://www.standingto gether.org.uk/dhr. Accessed 20 Apr 2020

Morris, K., Brandon, M., \& Tudor, P. (2015). Rights, Responsibilities and Pragmatic Practice: Family Participation in Case Reviews: Rights, Responsibilities and Pragmatic Practice. Child Abuse Review, 24(3), 198-209. https://doi.org/10.1002/car.2272

Mullane, F. (2017). The Impact of Family Members' Involvement in the Domestic Violence Death Review Process. In M. Dawson (Ed.), Domestic Homicides and Death Reviews: An International Perspective (pp. 257-286). Palgrave Macmillan.

Mullane, F., \& Welch, L. (2013). Advocacy After Fatal Domestic Abuse. In P. Patel (Ed.), Rebalancing the Scales: Prioritising Victims of Crime in the Criminal Justice System (pp. 29-40). n.p. https://paladinservice.co.uk/wp-content/uploads/2013/10/PritiPatel-MP-2013-Rebalancing-the-Scales-prioritising-victims-inthe-Criminal-Justice-System.pdf. Accessed 10 Dec 2020

Neuilly, M.-A. (2013). Putting the Public Back in Public Health: An Argument for the Articulation of Fatality Reviews and Coroners' Inquests. Homicide Studies, 17(4), 339-352. https://doi.org/10. $1177 / 1088767913494387$

New South Wales Domestic Violence Death Review Team. (2020). Domestic Violence Death Review Team Report 2017-2019. http:// www.coroners.justice.nsw.gov.au/Documents/2017-2019_ DVDRT_Report(online).pdf. Accessed 10 Apr 2020

Ngo, M., Matthews, L. R., Quinlan, M., \& Bohle, P. (2018). Bereaved Family Members' Views of the Value of Coronial Inquests Into Fatal Work Incidents. OMEGA - Journal of Death and Dying, 82(3), 446-466. https://doi.org/10.1177/0030222818819344

Office for National Statistics. (2020). Domestic abuse victim characteristics, England and Wales: Year ending March 2020. https://www. ons.gov.uk/peoplepopulationandcommunity/crimeandjustice/artic les/domesticabusevictimcharacteristicsenglandandwales/ingma rch2020. Accessed 07 Apr 2020

Office of the Chief Coroner Province of Ontario. (2019). Domestic Violence Death Review Committee 2018 Annual Report. https:// www.mcscs.jus.gov.on.ca/sites/default/files/content/mcscs/
docs/DVDRC\%202018\%20Annual\%20Report.pdf. Accessed 10 Apr 2020

Pawson, R., \& Tilley, N. (1997). Realistic Evaluation. Sage.

Payton, J., Robinson, A., \& Brookman, F. (2017). United Kingdom. In M. Dawson (Ed.), Domestic Homicides and Death Reviews: An International Perspective (pp. 91-123). Palgrave Macmillan.

Robinson, A. L., Rees, A., \& Dehaghani, R. (2019). Making connections: A multi-disciplinary analysis of domestic homicide, mental health homicide and adult practice reviews. The Journal of Adult Protection, 21(1), 16-26. https://doi.org/10.1108/ JAP-07-2018-0015

Rock, P. (2000). Homicide, Voluntary Organizations, and the State in England and Wales. Homicide Studies, 4(1), 37-62. https://doi. org/10.1177/1088767900004001003

Rock, P. E. (1998). After homicide: Practical and political responses to bereavement. Oxford University Press.

Rowlands, J. (2020a). Reviewing domestic homicide-International practice and perspectives. Winston Churchill Memorial Trust. https://www.wcmt.org.uk/users/jamesrowlands2019

Rowlands, J. (2020b). The ethics of victim voice in Domestic Homicide Reviews. Sentio, 2, 34-41.

Ryan, S. (2019). NHS Inquiries and Investigations; an Exemplar in Peculiarity and Assumption. The Political Quarterly, 90(2), 224228. https://doi.org/10.1111/1467-923X.12703

Sharp-Jeffs, N., \& Kelly, L. (2016). Domestic Homicide Review (DHR) Case Analysis. Standing Together Against Domestic Violence and London Metropolitan University. https://www.standingtogether. org.uk/dhr. Accessed 28 Nov 2018

Shaw, H., \& Coles, D. (2007). Unlocking the truth: Families' experiences of the investigation of deaths in custody. Inquest. https:// www.inquest.org.uk/unlocking-the-truth. Accessed 27 Nov 2018

Sheehan, B. E., Murphy, S. B., Moynihan, M. M., Dudley-Fennessey, E., \& Stapleton, J. G. (2015). Intimate Partner Homicide: New Insights for Understanding Lethality and Risks. Violence against Women, 21(2), 269-288. https://doi.org/10.1177/1077801214 564687

Snell, K., \& Tombs, S. (2011). 'How do you get your voice heard when no-one will let you?' Victimization at work. Criminology \& Criminal Justice, 11(3), 207-223. https://doi.org/10.1177/17488 95811401985

Spillane, A., Matvienko-Sikar, K., Larkin, C., Corcoran, P., \& Arensman, E. (2019). How suicide-bereaved family members experience the inquest process: A qualitative study using thematic analysis. International Journal of Qualitative Studies on Health and Well-Being, 14(1), 1563430. https://doi.org/10.1080/17482 631.2018 .1563430

Stame, N. (2004). Theory-based evaluation and types of complexity. Evaluation, 10(1), 58-76. https://doi.org/10.1177/1356389004 043135

Stauffer, J. (2015). Ethical loneliness: The injustice of not being heard. Columbia University Press.

Tomczak, P. (2018). Prison suicide: What happens afterwards?. Bristol University Press.

Walker, M., McGlade, M., \& Gamble, J. (2008). A domestic homicide review into the deaths of Julia and William Pemberton. West Berkshire Safer Communities Partnership. https://aafda.org. uk/public/storage/Resource\%20Items/domestic\%20homicide\% 20reviews/Pemberton-Homicide-Review-2008.pdf. Accessed 30 Jan 2019

Websdale, N. (Ed.). (2010). Fatality Review Bulletin Summer 2010. National Domestic Violence Fatality Review Initiative. http:// www.ndvfri.org/newsletters/NDVFRI_Newsletter_2010Summer. pdf. Accessed 01 Nov 2020

Websdale, N. (2012). Community, civic engagement, and democracy: The case of domestic violence fatality review. National Civic Review, 101(2), 27-33. https://doi.org/10.1002/ncr.21074 
Websdale, N. (2020). Domestic Violence Fatality Review: The State of the Art. In R. Geffner, V. Vieth, V. Vaughan-Eden, A. Rosenbaum, L. K. Hamberger, \& J. White (Eds.), Handbook of Interpersonal Violence Across the Lifespan (pp. 1-23). Springer.

Websdale, N., Ferraro, K., \& Barger, S. D. (2019). The domestic violence fatality review clearinghouse: Introduction to a new National Data System with a focus on firearms. Injury Epidemiology, 6(1), 6. https://doi.org/10.1186/s40621-019-0182-2
Zedner, L. (2020). 'Policing civility in public space and the exclusion of "uncivil" citizens.' In O. Beaud \& F. Saint-Bonnet (Eds.), La Citoyenneté comme appurtenance au corps politique. Panthéon-Assas University.

Publisher's Note Springer Nature remains neutral with regard to jurisdictional claims in published maps and institutional affiliations. 